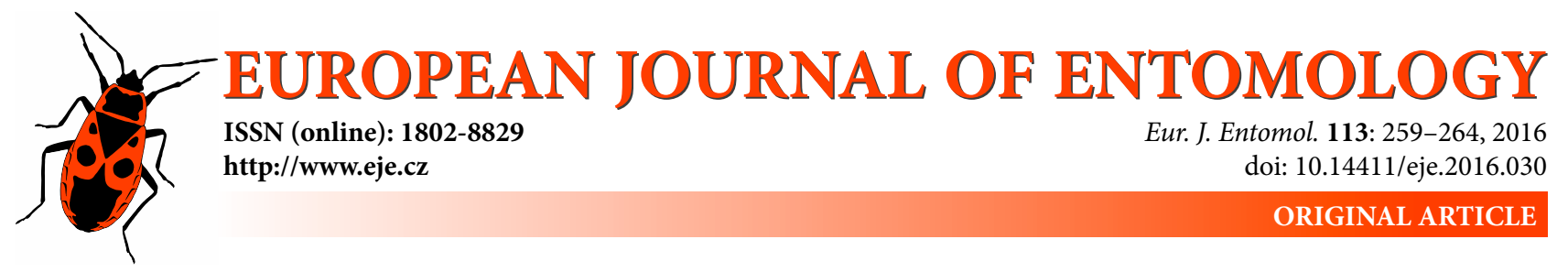

\title{
The effect of ambient temperature on larvae of Scatopsciara cunicularius (Diptera: Sciaridae) feeding on the thallose liverwort Marchantia polymorpha
}

\author{
WeERACHON SAWANGPROH ${ }^{1}$, JOHAN EKROOS $^{2}$ and Nils CRONBERG ${ }^{1}$ \\ ${ }^{1}$ Biodiversity, Department of Biology, Ecology Building, Lund University, 22362 Lund, Sweden; \\ e-mails: weerachon.sawangproh@biol.lu.se,nils.cronberg@biol.lu.se \\ ${ }^{2}$ Centre for Environmental and Climate Research, Lund University, Box 117, 22100 Lund, Sweden; \\ e-mail: johan.ekroos@cec.lu.se
}

Key words. Diptera, Sciaridae, Scatopsciara cunicularius, gnat larva, sciarid fly, biological control, Marchantia polymorpha

\begin{abstract}
Herbivory on liverworts is rarely reported. We studied the effects of feeding by larvae of the sciarid fly Scatopsciara cunicularius on the growth of the thalloid liverwort Marchantia polymorpha at two different constant temperatures, $12^{\circ} \mathrm{C}$ and $22^{\circ} \mathrm{C}$. Larvae reared at the lower temperature fed slower and over a longer period of time, which resulted in more damage and a greater reduction in the growth of the liverwort than that caused by those reared at the higher temperature. The reduction in growth of the liverwort was positively density-dependent in terms of number of larvae at both temperatures. These results indicate that the larvae of $S$. cunicularius are likely to be an effective means of controlling M. polymorpha, which is a common weed in plant nurseries and greenhouse cultures.
\end{abstract}

\section{INTRODUCTION}

Somewhat unexpectedly, we recently observed dipterous larvae boring into and feeding on living thalli of the liverwort, Marchantia polymorpha L. in an experimental greenhouse of the Department of Biology, Lund University. Based on morphological analysis of the adults, the borer turned out to belong to a family of tiny flies, Sciaridae (dark winged fungus gnats, sometimes called "sciarids"), more precisely a species known as Scatopsciara (Xenopygina) cunicularius Lengersdorf. This species was originally described by Lengersdorf (1943) as feeding on M. polymorpha in greenhouse environments in Germany. Until our rediscovery it was only known from the original description and it may have escaped attention due to its hidden life-style and difficulty of species identification, which are general features of sciarids (Sohier et al., 2012). We confirmed that $S$. cunicularius is able to complete its entire life-cycle feeding on liverworts as the only source of food (Sawangproh \& Cronberg, in press).

Sciaridae is composed of more than 2,000 species worldwide (Menzel \& Mohrig, 2000) and more than 600 species in Europe (Heller \& Menzel, 2010). The bodies and wing membranes of adult sciarids have a distinctly dark colouration (Mohrig \& Menzel, 2009). The wings are fragile, with a markedly "Y" shaped vein in each wing and the antennae are distinctly long and segmented (Cloyd \&
Sadof, 2010). Larval stages have different feeding preferences. Most sciarid larvae are phytosaprophagous, i.e. they feed on a wide range of organic matter in the soil and leaf litter (Menzel \& Mohrig, 2000) or decaying tree trunks or stumps (Shin et al., 2012). Larvae of some genera such as Bradysia and Lycoriella are phytophagous, which means that they tunnel into fresh plant tissue, in some cases infesting economically important crops or ornamental plants such as potato, wheat, red clover, alfalfa and pine seedlings, tulip bulbs, ferns, begonias, coleus, geraniums, cacti, young orchids, araca palm, dracaenas and shiitake mushrooms (Dennis, 1978; Mead, 1978; Hamlen \& Mead, 1979; Steffan, 1981; Shin et al., 2012).

In fact, few insects are known to feed on liverworts, probably because liverworts have oil bodies that contain essential oils that are thought to be a defence against herbivory (Vanderpoorten \& Goffinet, 2009). Our rediscovery has important theoretical implications because both the insects and the liverworts represent evolutionary lineages that are very old and thus the interaction could potentially be of ancient origin. However, Shin et al. (2013) hypothesized that herbivory in Sciaridae was the latest evolutionary step and $S$. cunicularius is not thought to belong to the most ancient Sciaridae groups. From a more practical point of view the insects may present a possible means of controlling $M$. polymorpha in plant nurseries. This liverwort 
is frequently a serious weed as it is a strong competitor for water and nutrients during propagation of horticultural and ornamental plants (Cronberg, 1990, 1991; Svenson, 2000; Fausey, 2003; Newby et al., 2007; Altland et al., 2008). The dispersal and spread of this liverwort can be reduced to some extent by a number of hygienic measures such as the use of clean pots and modified cultivation techniques (Cronberg, 1990, 1991). Still, herbicides are often used although $M$. polymorpha is resistant to the most common substances. Moreover, such methods are often impossible to use in ongoing cultures without putting the commercial crop at risk. Therefore a method for the biological control of $M$. polymorpha is urgently needed. The elaboration of an efficient method for controlling $M$. polymorpha requires an understanding of the biological and developmental characteristics of the sciarid S. cunicularius.

Based on our initial observations on greenhouse cultures it appeared that the expansion of the sciarid fly takes place during early summer, when the temperature reached a certain level. We therefore hypothesized that the life span of the juvenile stages of this insect is positively temperaturedependent. Based on observations on our greenhouse cultures we also hypothesized that herbivory is detrimental to the bryophyte as its growth is reduced and the risk of it suffering drought stress is increased. The aims of this study are thus to investigate the development of the sciarid fly $S$. cunicularius and quantify the effect of the feeding of its larvae on the thallose of the bryophyte M. polymorpha in a controlled environment at two temperatures.

\section{MATERIALS AND METHODS}

The sciarid fly larvae used in this study were obtained from thalli of M. polymorpha collected in a Lund University experimental greenhouse. The original provenance of the sciarid is unknown since it was unexpectedly observed in material of $M$. polymorph ssp. ruderalis collected during late 2010 by Nils Cronberg for a completely different purpose from a number of sites ranging from Utrecht (the Netherlands) in the south to Sundsvall (N Sweden) in the north, including both natural sites and plant nurseries.

To quantify and compare feeding damage, sciarid larvae were raised on $M$. polymorpha at two temperatures. We collected $3^{\text {rd }}$ and $4^{\text {th }}$ instar larvae of $S$. cunicularius from infested M. polymorpha thalli, which were transferred onto intact thalli in different numbers: 0 (= controls), 1 larva, 2 larvae, 3 larvae and 4 larvae, on 28 January 2014 (Table 1). Each thallus with a given number of larvae was then placed individually onto a moistened filter paper in a closed Petri dish. The Petri dishes were kept at one of

Table 1. The numbers of replications of larval herbivory by S. cunicularius on the thallose liverwort M. polymorpha.

\begin{tabular}{lcc}
\hline Treatment & \multicolumn{2}{c}{ No. of replications } \\
\cline { 2 - 3 } (No. of larvae per thallus) & The warm room & The cold room \\
\hline 0 & 4 & 5 \\
1 & 14 & 10 \\
2 & 5 & 9 \\
3 & 7 & 7 \\
4 & 3 & 2 \\
\hline Total & 33 & 33 \\
\hline
\end{tabular}

Numbers of replications are based on the treatments with complete observations of larval herbivory (from larval stage till pupal stage). two different temperatures: $22^{\circ} \mathrm{C}$ or $12^{\circ} \mathrm{C}$. The two culture rooms were set at the same photoperiod of $14 \mathrm{~L}: 10 \mathrm{D}$ (light source: a lamp with two Philips Master TL-D Super 80 18W/840 1SL fluorescent tubes; photon flux $39-50 \mu \mathrm{mol} \mathrm{m} \mathrm{m}^{-2} \mathrm{~s}^{-1}$ ). To monitor the ambient conditions in the Petri dish, one iButton ${ }^{\circledR}$ temperature/ humidity logger (DS1923) was placed inside one of the Petri dishes at each of the temperatures to log temperature and relative humidity (RH) every $30 \mathrm{~min}$.

To record larval feeding and larval development, Petri dishes were checked daily under a dissecting microscope. The filter papers in the Petri dishes were saturated gently by adding deionized water. Excess water was decanted off, if present. All thalli were photographed in order to quantify the area damaged by larval feeding every 6 days until the last larva had pupated.

We used the software package ImageJ, version 1.47 (National Institute of Health, USA, freely available from http://imagej.nih. gov/ij/), to measure the extent of damage to the thalli caused by larval feeding recorded in the photographs. Firstly, we used the "Strait Line selections" tool to calibrate a 5-mm distance in a photograph. Secondly, we chose "Freehand Selections" tool to delimit the damage area on the thallus. Finally, we calculated the damaged areas by using "Measure" tool. The photographs were also used to quantify the growth of the thalli during the experiment.

The analysis of deviance, a modified version of variance analysis accommodating unequal replication of effects, was done using Programme R version 3.1.2 (The R Foundation for Statistical Computing Platform, 2014) to investigate the effects of three factors (temperature, number of larvae and day of treatment) and the interactions among them on the extent of the damaged area on liverwort thalli. Comparisons of mean cumulative damaged areas on $M$. polymorpha thalli cultured in the warm and cold room were carried out in SPSS version 22 (IBM Corp., 2013) using an independent sample $t$ test at $\mathrm{P}<0.05$. The damaged areas recorded on $M$. polymorpha thalli caused by larvae of $S$. cunicularius on different days at the two temperatures were compared using oneway ANOVA, followed by a Tukey HSD test for multiple comparisons at $\mathrm{P}<0.05$. To check the effect of sciarid larval herbivory on the growth of liverworts, the mean percentage growth of liverworts infested with different numbers of larva(e) at the two temperatures were analyzed using a two-way ANOVA, and the mean percentage growth of liverworts in the different treatments compared using a Mann-Whitney U test (SPSS) at a significance level of 0.05 .

$\begin{gathered}\text { Percentage } \\ \text { growth of thalli }\end{gathered}=\frac{\text { Surface areas of thalli at } \mathrm{T}_{0}-\text { Surface areas of thalliat } \mathrm{T}_{\mathrm{p}}}{\text { Surface areas of thalliat } \mathrm{T}_{0}} \times 100$

where, $T_{0}$ is the time before larval infestation and $T_{p}$ is the time of pupation of the last larva in a particular Petri dish.

\section{RESULTS}

\section{Effect of the feeding of sciarid larvae on liverwort thallus damage}

The final design of the experiment was somewhat imbalanced (Table 1), since larvae died in some replicates, which therefore had to be abandoned. As we had very few larvae there are fewer replicates of the treatment with four larvae. Despite this, the results are clear. In each of the two constant temperature regimes $\left(22.6 \pm 1.7^{\circ} \mathrm{C}\right.$ in the warm room, $12.3 \pm 0.6^{\circ} \mathrm{C}$ in the cold room), sciarid larvae damaged the $M$. polymorpha thalli by tunneling and feeding on the chlorophyllous tissue. The three-way ANOVA revealed that area of damage was very highly significantly 


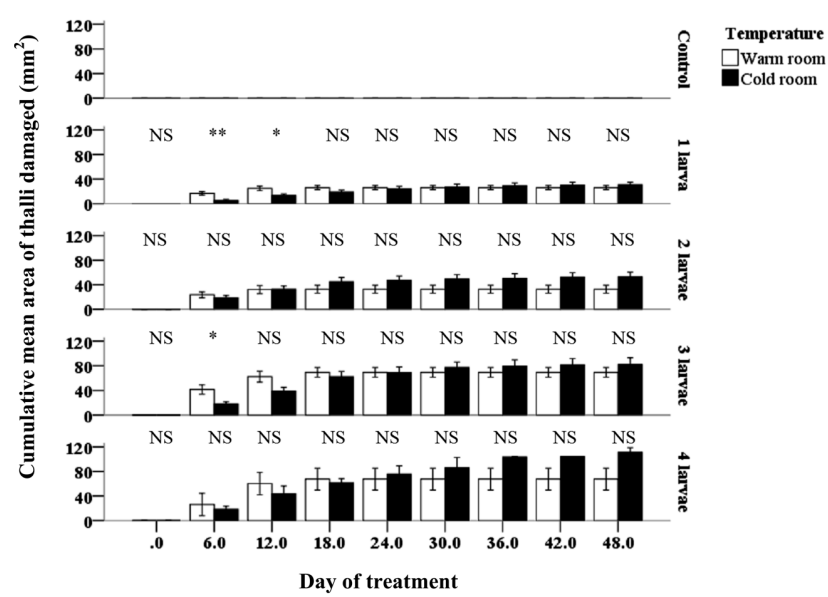

Fig. 1. Relationships of the cumulative mean area of M. polymorpha thalli damaged when infested with different numbers of larvae of $S$. cunicularius recorded at different intervals of time in warm and cold rooms. The damaged areas plotted are the mean \pm SE and the comparison of the extent of the damaged areas on thalli recorded in the warm and cold rooms were tested by independent sample $t$ tests at a significant level of 0.05 .

associated with day of treatment and number of larvae that infested the bryophyte thalli, but not temperature (Table 2 ). The interactions between day of treatment $\times$ temperature and temperature $\times$ number of larvae also proved very highly significant, but not day of treatment $\times$ number of larvae. Finally, we found a highly significant three-way interaction (Table 2).

\section{Effect of ambient temperature on sciarid larval herbivory}

The extent of the area of liverwort thalli damaged increased with the number of larvae and day of treatment in both the warm and cold room cultures (Fig. 1). The area damaged was larger in the warm room culture than in the cold room culture 6-18 days after larval infestation (Fig. 2 ). After day 18, the damaged area did not increase in the warm room because all the larvae had pupated (the first and the last pupation occurred between days 12-18; Fig. 2 ). In the cold room culture the first pupation occurred around day 18 in the 2-larvae treatment and around day 24 in the other treatments. The last pupation occurred as late as around day 48 in the cold room (Fig. 2). The larvae kept in the cold room damaged a larger area of the thallus because they fed for longer (Fig. 2).

Table 2. Analysis of deviance for the effects of days of treatment, temperature and number of larva(e) on damaged area of $M$. polymorpha thalli caused by herbivory of $S$. cunicularius.

\begin{tabular}{lrcc}
\hline Factor & $\begin{array}{c}\text { Deviance } \\
\left(\mathrm{X}^{2} \text { approx. }\right)\end{array}$ & $\begin{array}{c}\mathrm{Pf} \\
\text { value }\end{array}$ \\
\hline Days of treatment & 1143.9256 & 7 & $* * *$ \\
Temperature & 0.4466 & 1 & $\mathrm{NS}$ \\
No. of larva(e) & 130.8854 & 4 & $* * *$ \\
Factor interaction & 304.6050 & 7 & $* * *$ \\
Days of treatment $\times$ Temperature & 565.5926 & 28 & $* * *$ \\
Days of treatment $\times$ No. of larva(e) & 3.1961 & 4 & $\mathrm{NS}$ \\
Temperature $\times$ No. of larva(e) & 140.0528 & 28 & \\
Days of treatment $\times$ Temper. $\times$ No. of larva(e) & 140.052 \\
\hline
\end{tabular}

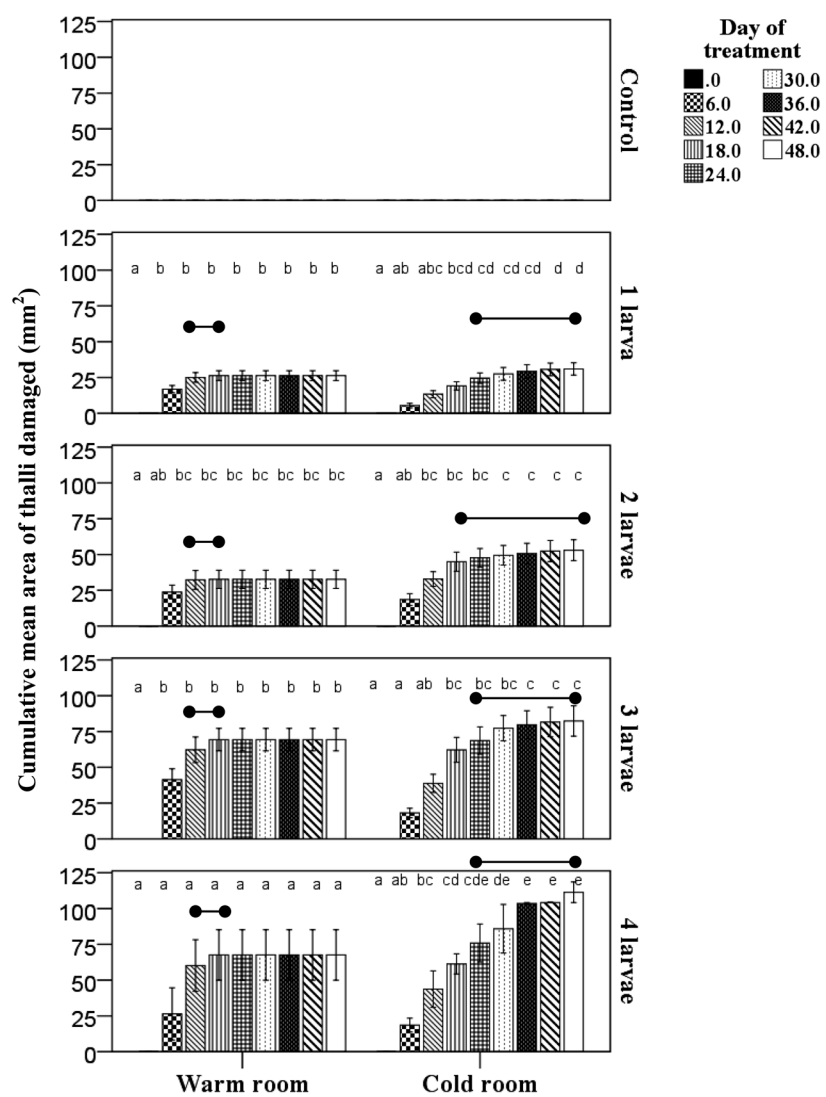

Fig. 2. The effect of the number of larval $S$. cunicularius and the day of treatment on the extent of the area of $M$. polymorpha thalli damaged at two different temperatures. Columns are the means \pm $\mathrm{SE}$, the same letter(s) above the means of the different treatments in the same culture room indicate no significant difference in the area damaged according to Tukey HSD procedure $(p<0.05)$ and the black dots connected by a line indicate the first and the last pupation of the larvae in each treatment.

\section{Effect of sciarid larval infestation on growth of liverwort thalli}

The two-way ANOVA based on the change in surface area of liverwort thalli from before infestation and that after pupation, revealed significant effects of both the number of larvae and temperature. The growth was negatively dependent on the number of larvae and positively dependent on temperature, and there was no significant interaction between these two factors (Table 3). The liverworts that were not infested with larvae (control group) grew continuously at both temperatures but those in the warm room grew faster than those in the cold room (Fig. 3). After larval infestation, the liverworts ceased growing as the damaged areas were not compensated by fresh growth in both

Table 3. Two-way ANOVA for analysis of growth of M. polymorpha thalli after sciarid larval infestation with different numbers in two contrasting temperature regimes.

\begin{tabular}{lrrcc}
\hline Source & SS & df & F & P value \\
\hline Temperature & 1480.7 & 1 & 8.2040 & ${ }^{* *}$ \\
No. of larva(e) & 4704.6 & 4 & 6.5167 & ${ }^{* * *}$ \\
Temperature $\times$ No. of larva(e) & 1022.4 & 4 & 1.4163 & NS \\
Error & 10107.0 & 56 & & \\
\hline
\end{tabular}




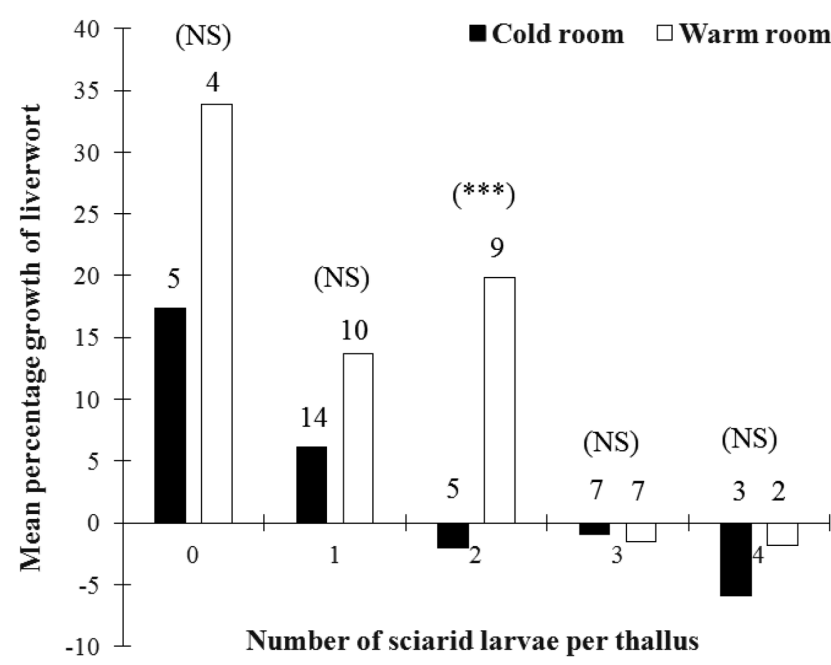

Fig. 3. The relationships between mean area of the liverwort damaged and the number of sciarid larvae per thallus recorded in the two contrasting temperature regimes. The percentage growth of the liverworts was determined by the difference in the surface area of the thallus $\left(\mathrm{mm}^{2}\right)$ on the day before larval infestation $\left(\mathrm{T}_{0}\right)$ and that recorded when the insects pupated $\left(T_{p}\right)$. The columns are the mean values of thallus surface area $\left(\mathrm{mm}^{2}\right)$. The numbers of replications in each treatment are at the top of each column.

the cold and warm rooms, and depending on the number of larvae the thalli even tended to decrease in size (Fig. 3).

\section{DISCUSSION}

To our knowledge, there are very few studies that compare the growth of sciarid larvae at different temperatures and none that quantify the effect on the host plant. We found that ambient temperature affected not only the survival and larval development of the sciarid fly S. cunicularius, but also its feeding activity and the damage it caused to the thallose liverwort $M$. polymorpha. The larval feeding period was significantly prolonged in the cold regime compared to the warm regime, which resulted in more damage and strongly decreased growth of the M. polymorpha thalli.

\section{Effect of ambient temperature on sciarid larval herbivory}

Our study shows that the feeding rate and the larval development rate of $3^{\text {rd }}$ and $4^{\text {th }}$ instar were higher at $22^{\circ} \mathrm{C}$ than at $12^{\circ} \mathrm{C}$. Larvae reared at a constant temperature of about $22^{\circ} \mathrm{C}$ consumed the thallus faster (Fig. 1) and reached pupal stage earlier than those reared at a temperature of about $12^{\circ} \mathrm{C}$. Consequently, larvae reared at the lower temperature consumed more liverwort tissue before they reached the pupal stage than those reared at the higher temperature. The last pupation occurred on day 22 at $22^{\circ} \mathrm{C}$ and day 38 at $12^{\circ} \mathrm{C}$ (ca. $73 \%$ longer) and the last adult emergence was recorded on day 28 at $22^{\circ} \mathrm{C}$ and day 53 at $12^{\circ} \mathrm{C}$ (ca. $89 \%$ longer) (Fig. 2). In comparison, Wilkinson \& Daugherty (1970) report that the temperature range over which the sciarid fly Bradysia impatiens can complete development from egg to adult is from $12.8^{\circ} \mathrm{C}$ to $32.2^{\circ} \mathrm{C}$, with the optimal temperature for larval development a constant $23.9^{\circ} \mathrm{C}$, i.e. the temperature at which percentage larval survival is highest. This indicates that temperatures outside the range $12-32^{\circ} \mathrm{C}$, can negatively affect sciarid larval physiology. However, the mean periods of development and adult longevity of $B$. impatiens were significantly shorter at the high temperature than that at the low temperature (Wilkinson \& Daugherty, 1970). These differences are probably explained by changes in metabolic efficiency in which at high temperatures the speed of the chemical reactions is higher than at low temperatures, which consequently results in increases in the rates of growth and development (Begon et al., 2005). It is also possible that the slower growth of the thalli at the low temperature is associated with an increased accumulation of secondary substances, or development of tougher cell walls that reduce the nutritive value of the liverwort tissue for the larvae. On the other hand, despite the prolonged growth and development of sciarid larvae reared at the low temperature, adults seemed to be larger than those reared at the high temperature (pers. observ.). This may be due to the consumption of more liverwort tissue or by qualitative differences in the liverwort tissue, for example, when exposed to low temperatures the cellular content of essential fatty acids, such as linolenic acid and eicosapentaenoic acids, is higher in Marchantia (Saruwatari et al., 1999).

\section{Effect of sciarid larval infestation on growth of liverwort thalli}

In this study, the decrease in the thallus growth of the liverwort was dependent on the number of larvae that infested a thallus in both temperature regimes. The effect of larval herbivory on the liverwort growth was more pronounced at the low than the high temperature, in which the growth of the liverwort thalli infested with 2, 3 and 4 larvae decreased in growth at the low temperature, whereas only thalli infested with 3 and 4 larvae at the high temperature decreased in growth (Fig. 3). To decrease the growth of the liverwort at the low and high temperatures an infestation of at least 2-3 larvae per thallus was required. The feeding of the larvae on the thalli may affect the liverwort in several different ways. The liverwort thallus is multilayered, with a protective upper layer with small pores that allow the movement of air and vapour into an air-filled space divided into separate chambers (each with one pore), where the chlorophyllous cells are located, below which there is a more compact layer of parenchymatous tissue, including cells that store oil bodies, below which there is a protective layer with scales and rhizoids ventrally. The larvae primarily feed on the two inner layers. Feeding on the chlorophyllous tissue means that photosynthesis is reduced and important nutrients consumed. Feeding also opens connections between air chambers so that they are less protected against drought. Transportation of water inside the thallus is also likely to be reduced. Humidity was kept high in the present experiment, but we observed that infested thalli tended to dry out under the normally drier conditions prevailing in experimental greenhouses. 


\section{Other factors affecting larval herbivory of liverworts}

From our observations, the rate of feeding of larvae tended to decrease or stop when thalli dried out. Frequently, larvae reared at $12^{\circ} \mathrm{C}$ were observed crawling on the surface of the filter paper or along the inner surface of the lid of Petri dishes, probably trying to find a warmer place. Based on our results, larval survival to maturity at $12^{\circ} \mathrm{C}$ was lower (ca. $66 \%$ ) than at $22^{\circ} \mathrm{C}$ (ca. $73 \%$ ). This indicates that exposure to a temperature of $12^{\circ} \mathrm{C}$ was more stressful for larvae than $22^{\circ} \mathrm{C}$. Larval mortality was highest shortly after transferring larvae from an old thallus in the greenhouse onto a new intact thallus at both temperatures. After successful accommodation to their new environments, larval mortality was low at both $12{ }^{\circ} \mathrm{C}$ and $22^{\circ} \mathrm{C}$. In addition, once the larvae pupated, adults emerged from all the pupae at both temperatures. This indicates that both $12^{\circ} \mathrm{C}$ and $22^{\circ} \mathrm{C}$ are suitable for pupal development but at both temperatures some adults had abnormal wrinkled wings, as previously reported by Wilkinson \& Daugherty (1970).

\section{Application of the results of this life history study of a sciarid fly for controlling liverworts}

This study is a substantial and the first contribution to the knowledge of the biology and life history of the sciarid fly S. cunicularius since its description (Lengersdorf, 1943). Furthermore, we propose that $S$. cunicularius can be promoted as a promising future biological control agent for use against $M$. polymorpha. Our results indicate that the larvae of this sciarid fly can seriously damage this liverwort. The damage appears to make the liverwort very susceptible to desiccation. The damaged tissue is also likely to be subject to secondary attack by other phytophagous organisms and infection by fungi. We also show that the larvae are active at temperatures that are maintained in a wide range of plant cultures.

The most efficient way to carry out biological control is probably to release adults in greenhouses. It seems to be easy to propagate this insect under controlled conditions. To rapidly produce many adults the temperature should be kept above $20^{\circ} \mathrm{C}$. That $S$. cunicularius only feeds on $M$. polymorpha can be assumed because this species has never been found elsewhere in faunistic surveys or reported infesting greenhouse crops. However, more studies are necessary to further understand how the plant protects itself and also to determine the distribution of this sciarid in natural habitats and how frequently it occurs in commercial greenhouses infested with Marchantia.

\section{CONCLUSIONS}

Overall, our results reveal that larvae of $S$. cunicularius are phytophagous and feed by tunnelling in to its host $M$. polymorpha. Larval herbivory by $S$. cunicularius is density-and temperature-dependent. At a warm temperature, the larvae feed faster than at a cold temperature. However, at the cold temperature, the larvae feed slower and took longer to develop and as a consequence a larger area of M. polymorpha was damaged by each larva. Under cold condition, the life stages of $S$. cunicularius are prolonged.
ACKNOWLEDGMENTS. We would like to thank K. Heller for help with the identification. We are grateful to E. McFarlane, the language editor and two anonymous reviewers for their valuable help and suggestions for improving this manuscript.

\section{REFERENCES}

Altland J.E., Wehtje G., McKee M.L. \& Gilliam C.H. 2008: Liverwort (Marchantia polymorpha) response to Quinoclamine in a pine bark substrate. - Weed Sci. 56: 762-766.

Begon M., Townsend C.R. \& Harper J.L. 2005: Ecology: From Individuals to Ecosystems. Wiley-Blackwell, Malden, Oxford, $752 \mathrm{pp}$.

Cloyd R.A. \& Sadof C.S. 2010: Fungus Gnats and Shore Flies. Purdue Cooperative Extension Service Bulletin: E-111-W. URL: https://extension.entm.purdue.edu/publications/E-111. pdf (last accessed 24 Feb 2016).

CRONBerg N. 1990: Åtgärder för kontroll av lungmossa i plantskolemiljö I. - Plantnytt 1990: 1-4.

CRONBerg N. 1991: Åtgärder för kontroll av lungmossa i plantskolemiljö II. - Plantnytt 1991: 1-4.

DenNIS D.J. 1978: Observations of fungus gnat damage to glasshouse curcurbits. - N.Z. J. Exp. Agric. 6: 83-84.

FAUSEY J.C. 2003: Controlling liverwort and moss now and in the future. - Horttechnology 13: 35-38.

Hamlen R.A. \& MEAD F.W. 1979: Fungus gnat larval control in greenhouse plant production. - J. Econ. Entomol. 72: 269271.

Heller K. \& Menzel F. 2010: Fauna Europaea: Sciaridae. In Beuk P.L.T. \& Pape T. (eds): Fauna Europaea: Diptera, Nematocera. Fauna Europaea. Database Version 2.3. URL: http:// www.faunaeur.org (last accessed 30 March 2015).

IBM CoRP. ReLEASEd 2013: IBM SPSS Statistics for Windows, Version 22.0. IBM Corp., Armonk, NY.

LENGERSDORF F. 1943: Drei neue Lycoria- (Neosciara-) Arten Diptera. - Mitt. Entomol. Ges. Halle 20: 3-6.

MEAD F.W. 1978: Darkwinged fungus gnats, Bradysia spp., in Florida greenhouses (Diptera: Sciaridae). - Entomol. Circ. 186: $1-4$.

Menzel F. \& Mohrig W. 2000: Revision der paläarktischen Trauermücken (Diptera, Sciaridae). — Stud. Dipterol. (Suppl.) 6[1999]: $761 \mathrm{pp}$.

Mohrig W. \& Menzel F. 2009: Sciarid flies from Dominicant Amber (Diptera, Sciaridae). - Beitr. Entomol. 55: 319-361.

Newby A., Altland J.E., Gilliam C.H. \& Wehtje G. 2007: Preemergence liverwort control in nursery containers. - Horttechnology 17: 496-500.

SARUwATARI M., TAKIO S. \& ONO K. 1999: Low temperature-induced accumulation of eicosapentaenoic acids in Marchantia polymorpha cells. - Phytochemistry 52: 367-372.

SAWANGPROH W. \& Cronberg N. in press. Life history traits of the liverwort herbivore Scatopsciara cunicularius (Diptera: Sciaridae). - Ann. Entomol. Soc. Am.

SHIN S., LeE H.S. \& LeE S. 2012: Dark winged fungus gnats (Diptera: Sciaridae) collected from shiitake mushroom in Korea. - J. Asia Pac. Entomol. 15: 174-181.

Shin S., Jung S., Menzel F., Heller K., Lee H. \& Lee S. 2013: Molecular phylogeny of black fungus gnats (Diptera: Sciaroidea: Sciaridae) and the evolution of larval habitats. - Mol. Phylogenet. Evol. 66: 833-846.

Sohier C., Dekoninck W., Menzel F., Versteirt V. \& Grootaert P. 2012: Larval habitat characteristics along the Scheldt estuarium of Bradysia ocellaris (Comstock), a black fungus gnat (Diptera: Sciaridae) of economic importance. - Belg. J. Zool. 142: 127-129. 
Stefan W.A. 1981: Sciaridae. In McAlpine J.F., Peterson B.V., Shewell G.E., Teskey H.J., Vockeroth J.R. \& Wood D.M. (eds): Manual of Nearctic Diptera. Vol. 1. Monograph 27, Agriculture Canada, Ottawa, 674 pp.

Svenson S. 2000: Control of Liverworts and Mosses in Greenhouses. URL: http://bryophytes.science.oregonstate.edu/ page25.htm (last accessed 19 Feb. 2014).
VANDERPOoRTen A. \& Goffinet B. 2009: Introduction to Bryophytes. Cambridge University Press, Cambridge, 303 pp.

Wilkinson J.D. \& Daugherty D.M. 1970: Comparative development of Bradysia impatiens (Diptera: Sciaridae) under constant and variable temperatures. - Ann. Entomol. Soc. Am. 63: 1079-1083.

Received November 24, 2015; revised and accepted February 4, 2016 Published online March 2, 2016 